\title{
Pascal DuPuY, Face à la Révolution et l'Empire. Caricatures anglaises (1789-1815)
}

Collections du Musée Carnavalet, Paris, co-édition Paris-Musées, Nicolas Chaudin et Musée Carnavalet, 2008, 192 p., ISBN 9782759 6000601, $55 €$

\section{Annie Duprat}

\section{(2) OpenEdition}

\section{Journals}

\section{Édition électronique}

URL : https://journals.openedition.org/ahrf/11581

DOI : 10.4000/ahrf. 11581

ISSN : 1952-403X

Éditeur :

Armand Colin, Société des études robespierristes

\section{Édition imprimée}

Date de publication : 1 octobre 2009

Pagination : 193-194

ISBN : 978-2-200-92560-4

ISSN : 0003-4436

Référence électronique

Annie Duprat, «Pascal Dupur, Face à la Révolution et l'Empire. Caricatures anglaises (1789-1815) », Annales historiques de la Révolution française [En ligne], 358 | octobre-décembre 2009, mis en ligne le 29 juillet 2010, consulté le 24 avril 2022. URL : http://journals.openedition.org/ahrf/11581 ; DOI : https:// doi.org/10.4000/ahrf.11581

Ce document a été généré automatiquement le 24 avril 2022.

Tous droits réservés 


\section{Pascal DUPUY, Face à la Révolution et l'Empire. Caricatures anglaises (1789-1815)}

Collections du Musée Carnavalet, Paris, co-édition Paris-Musées, Nicolas Chaudin et Musée Carnavalet, 2008, 192 p., ISBN 9782759 6000601, $55 €$

\section{Annie Duprat}

\section{RÉFÉRENCE}

Pascal DuPuY, Face à la Révolution et l'Empire. Caricatures anglaises (1789-1815), Collections du Musée Carnavalet, Paris, co-édition Paris-Musées, Nicolas Chaudin et Musée Carnavalet, 2008, 192 p., ISBN 9782759 6000601, $55 €$

1 Depuis la soutenance en 1998 de sa thèse, magistrale tant par la taille (pas moins de sept volumes somptueusement illustrés de nombreuses reproductions en couleurs), que par l'originalité de la démarche, Pascal Dupuy n'a cessé d'interroger les sources anglaises concernant la Révolution française et ses interactions avec l'histoire du Royaume-Uni (L'Angleterre face à la Révolution : la représentation de la France et des Français à travers la caricature, 1789-1802, doctorat, dir. Claude Mazauric, Université de Rouen). Pour réaliser ce travail, il a longuement exploré, outre les collections françaises bien connues des amateurs et des chercheurs comme le cabinet des estampes de la BNF et celui du Musée Carnavalet à Paris, les immenses ressources du British Museum de Londres et celles de plusieurs prestigieuses bibliothèques aux États-Unis, Yale et Harvard entre autres. Mais il s'est trouvé ensuite devant la quasi-impossibilité de publier sa thèse in extenso en raison du coût très élevé des droits de reproduction et des frais de publication, en particulier lorsque l'impression en couleurs en nécessaire. C'est pourquoi il faut saluer Philippe de Carbonnières, directeur de la collection, d'avoir accueilli le travail de Pascal Dupuy, qui prend la suite de deux ouvrages dus à Philippe de Carbonnières : Lesueur, gouaches révolutionnaire, Collections du Musée Carnavalet, 2005, 
et Prieur, Les tableaux historiques de la Révolution française, catalogue raisonné des dessins originaux. Collections du Musée Carnavalet, Paris, 2006. Le prochain opus sera un livre de Rolf Reichardt consacré aux images de la Bastille.

2 Nourri des réflexions développées dans la thèse, ce livre est cependant très différent, par une extension chronologique plus grande (1789-1815) mais aussi par le fait que, nécessités de la collection aidant, les caricatures qui forment le catalogue raisonné (p. 87-182), soigneusement présentées et explicitées chacune sur une double page, ont été choisies parmi les fonds du Musée Carnavalet. Pour autant, Pascal Dupuy n'a pas sacrifié les images qui étaient importantes pour son propos mais absentes des collections du Musée.

Elles figurent dans la première partie du livre, découpée elle-même en trois chapitres distincts («Du caprice d'artiste à l'âge d'or de la caricature politique», p. 15-23, "Production, diffusion et réception des caricatures anglaises », p. 24-43, et «Presse et caricature en Europe », p. 44-57).

Bien que le public anglais, aux XVIII et $\mathrm{XIX}^{\mathrm{e}}$ siècles, "plébiscite » les caricatures (la première image présentée est le célèbre Very slippy weather, réalisé par James Gillray en 1808 et conservé au British Museum, qui montre la foule amassée devant la boutique de Mrs Humprey sur St James Street à Londres), historiens et critiques d'art les ont longtemps négligées. L'auteur explique comment, grâce à la liberté d'expression régnant en Angleterre, de grands artistes (Gillray, bien sûr, mais aussi Cruikshank, Rowlandson ou encore Richard Newton, pour ne citer que les plus ingénieux), ont rendu compte des événements extraordinaires qui se déroulaient sous leurs yeux. La méconnaissance de cette source spécifique nous surprend aujourd'hui dans la mesure où des lettres de noblesse ont été données à l'art de la caricature qui entre de plain pied comme une source incontournable pour les historiens culturalistes. En effet, comment ne pas voir l'estampe citée précédemment, Very slippy weather sans avoir le regard attiré par toutes les caricatures exposées sur la devanture de la boutique de Mrs Humphrey, sur St James Street. On y reconnaît les plus grands succès du moment, dont le fameux tout petit ogre corse toisé à la longue vue par George III d'Angleterre sur The King of Brobdingnag and Gulliver (1803) par Gillray, l'une des multiples caricatures publiées contre Napoléon à travers l'Europe. Ce document est judicieusement placé en regard du précédent. Cet ensemble participe de la diffusion et de la réception de l'information politique du moment, tout comme d'autres images peuvent nous renseigner sur les figures du corps, les variétés des costumes ou des pratiques quotidiennes, comme l'alimentation ou la toilette.

5 Mis à part Gillray, fidèle à sa marchande-libraire Mrs Humphrey, les artistes vont vers l'éditeur le plus offrant, car les caricatures anglaises sont produites à un coût assez élevé - à l'exception sans doute des œuvres de William Holland - et touchent, de ce fait, les classes moyennes et supérieures. Publiées fréquemment en séries thématiques, elles sont facilement diffusées ce qui permet à des spectateurs plus désargentés d'en prendre connaissance. Des décennies avant la période révolutionnaire, Montesquieu avait déjà salué les bienfaits de la liberté d'expression dans ses Notes sur l'Angleterre en prenant pour exemple la diffusion des caricatures les plus caustiques.

6 Les caricatures montrent le jeu des regards croisés entre une Angleterre riche, puissante, qui en devient obèse, et une France, riche de ses discours mais appauvrie par la Révolution au point de dévorer des enfants cuits à la broche. Par ce biais, on observe aussi comment se constituent les stéréotypes nationaux, ici un John Bull rougeaud 
dominant un petit marquis français, The French flop. Ces gravures ont trouvé un écho dans la publication London und Paris, pour une grande part consacrée aux dessins d'humour. Les caricatures y sont traduites et transposées, à l'exemple de la célèbre gravure consécutive à l'épisode de Varennes, Le Gourmand. La caricature, longuement expliquée p. 95, œuvre de John Nixon et d'Isaac Cruikshank est d'origine anglaise et non française comme on a pu l'écrire parfois.

7 Livre d'histoire bien documenté et agréable à lire, l'ouvrage de pascal Dupuy, bien édité, est aussi un livre d'histoire de l'art, dont les notices précisent les infimes détails événementiels nécessaires à la compréhension des caricatures. 